\title{
PRODUTOS NATURAIS DE ALGAS MARINHAS E SEU POTENCIAL ANTIOXIDANTE E ANTIMICROBIANO
}

\author{
INGRIDY SIMONE RIBEIRO CABRAL* \\ LIGIANNE DIN SHIRAHIGUE* \\ LIA FERRAZ DE ARRUDA* \\ SOLANGE TEREZINHA CARPES** \\ MARÍLIA OETTERER ${ }^{\star \star *}$
}

\begin{abstract}
Esta revisão de literatura teve como objetivo apresentar os produtos de algas marinhas disponíveis no mercado, as atividades antioxidante e antimicrobiana por elas apresentadas, os principais compostos envolvidos nessas bioatividades, além de aspectos fundamentais sobre a exploração e comercialização desses produtos naturais. Os dados descritos na literatura evidenciam o grande potencial das algas marinhas como fontes naturais de ingredientes funcionais. O estudo da composição química, além da descoberta dos mecanismos de ação que envolvem as atividades biológicas das diversas espécies de algas, será interessante fonte de dados para a exploração de novas drogas de interesse para as indústrias farmacêutica e de cosméticos, bem como de novos ingredientes funcionais para a indústria alimentícia.
\end{abstract}

* Doutorandas em Ciências, Centro de Energia Nuclear na Agricultura, Universidade de São Paulo (CENAUSP), Piracicaba, São Paulo, Brasil (e-mail: ingridyribeiro@yahoo.com.br; ligianneds@yahoo.com.br; liaferraz2000@yahoo.com.br).

** Professora, Departamento de Química Tecnológica, Universidade Tecnológica Federal do Paraná (UTFPR), Campus Pato Branco, Pato Branco, PR (e-mail: carpes@utfpr.edu.br).

*** Professora Titular, Departamento de Agroindústria, Alimentos e Nutrição, Escola Superior de Agricultura "Luiz de Queiroz" (ESALQ- USP), Piracicaba, SP (e-mail: moettere@esalq.usp.br). 


\section{INTRODUÇÃo}

As algas são os organismos aquáticos mais antigos do planeta, havendo evidências de sua existência no período pré-cambriano (3,5 bilhões de anos, aproximadamente). As algas, por serem organismos fotossintetizantes, são responsáveis pela estruturação da atmosfera terrestre, possibilitando a vida de todos os seres vivos aeróbicos sobre a superfície do planeta pela produção de oxigênio molecular e a consequente formação da camada de ozônio que filtra os raios ultravioleta (UV). São organismos eucariotos que apresentam clorofila a e um talo não diferenciado em raiz, caule ou folhas. No ambiente aquático, as algas podem fazer parte dos bentos (indivíduos fixos no substrato) ou plâncton (indivíduos suspensos na água) (HORTA, 2000).

As algas marinhas apresentam importância, tanto sob o ponto de vista econômico, como ambiental e social. As algas podem realizar a manutenção do equilíbrio biológico nos ambientes aquáticos, ocasionando a continuidade da fauna existente, que pode ser utilizada pela humanidade como fonte de alimento e de matéria-prima. Algumas espécies são empregadas como indicadoras da qualidade dos sistemas aquáticos para os quais, inclusive, já foi sugerido um "índice de poluição" baseado nos gêneros de algas presentes: quanto menos diversificada a população, maior a poluição do sistema (VIDOTTI e ROLLEMBERG, 2004). As macroalgas marinhas vêm sendo utilizadas há milênios pelos povos orientais como parte importante de sua dieta alimentar e assumem grande significado social e econômico em vários países da Ásia, os quais podem responder por até $98 \%$ da produção mundial de algas (ROCHA, 2001).

Apenas três tipos de compostos encontrados em algas são explorados comercialmente: (1) alginatos, o ácido manurônico e o ácido gulurônico contendo polímeros a partir de algas pardas; (2) ágar, a D-galactose e o 3,6-anidro-L-galactose contendo polímeros que são isolados a partir de algas vermelhas, e (3) carragenas (CAMPO et al., 2009).

As algas são divididas em algas vermelhas (Rhodophyta), pardas (Phaeophyta) e verdes (Chlorophyta) (VIDOTTI e ROLLEMBERG, 2004). Os gêneros mais importantes compreendem Porphyra, Chondrus, Rhodymenia, Hypnea, Gracilaria, Laurência, Iridae (vermelhas); Undaria, Durvillaea, Ecklonia, Sargassum, Turbinaria (pardas); Ulva, Enteromorpha, Monostroma e Gaulerpa (verdes) (DHARGALKAR e VERLECAR, 2009).

A composição química das diferentes algas demonstra que, em geral, todas apresentam valor nutricional satisfatório, sendo fontes de proteínas, carboidratos, fibras, minerais e vitaminas. Além disso, são pouco calóricas e apresentam baixo teor de gordura. São excelentes fontes de vitaminas $A, B_{1}, B_{12}, C, D$ e $E$, riboflavina, niacina, ácidos pantotênico e fólico e minerais, tais como $\mathrm{Ca}, \mathrm{P}, \mathrm{Na}$ e K (DHARGALKAR e VERLECAR, 2009).

Como os outros alimentos de origem vegetal, as algas marinhas contêm todos os tipos de vitaminas e constituem fonte natural desses nutrientes para o homem. Apresentam carotenoides, alguns com atividade de provitamina $A$ e vitaminas $B$ e $C$, tanto quanto frutas, verduras e legumes comestíveis. As algas também representam fonte interessante de compostos com atividade biológica como, por exemplo, os fenólicos, tanto os halogenados, quanto os sulfatados e bromados, que podem ser utilizados como ingredientes funcionais (ZHANG et al., 2004; OH et al., 2008).

Sousa et al. (2008) estudaram 32 espécies de algas marinhas das divisões Chlorophyta, Rhodophyta e Phaeophyta como fontes de $\alpha$ e $\beta$-caroteno e de $\alpha$-tocoferol. Nesse estudo, com relação aos carotenoides provitamina $A$ e vitamina $E$, os maiores teores foram encontrados nas algas verdes, seguidas pelas pardas e vermelhas.

Campos, Barbarino e Lourenço (2010) cultivaram 10 espécies de microalgas marinhas de diferentes grupos taxonômicos e compararam o seu crescimento e a sua composição química. Verificaram diferenças na velocidade de crescimento, com espécies de células menores crescendo mais rapidamente que microalgas maiores. Teores de proteínas, carboidratos, lipídeos e pigmentos fotossintetizantes variaram amplamente entre as espécies, sendo as proteínas as substâncias mais abundantes. Todas as espécies apresentaram concentrações de aminoácidos semelhantes, 
destacando-se os ácidos aspárticos e glutâmicos. Algumas espécies apresentaram altas concentrações de ácidos graxos de importância econômica, como os ácidos eicosapentaenoico e linoleico. Entretanto, é interessante mencionar que a presença desses compostos pode ser influenciada pelos parâmetros de crescimento, tais como a temperatura da água de cultivo, salinidade, luz e nutrientes.

Algas marinhas contém significativa quantidade de polissacarídeos solúveis (GÓMEZORDÓÑEZ, JIMÉNEZ-ESCRIG e RUPÉREZ, 2010), em sua maioria não digeridos pelos seres humanos, cujo trato gastrointestinal não produz as enzimas necessárias para a sua degradação. Portanto, podem ser considerados como fibras dietéticas. Sob o ponto de vista nutricional, algas são interessantes devido ao seu alto teor de fibra alimentar (33-75\%).

Segundo Kadam e Prabhasankar (2010), os polissacarídeos de algas apresentam maior capacidade de retenção de água (WHC) do que as fibras celulósicas e o interesse em hidrocoloides de algas para a nutrição humana deve-se à sua atuação como fibra dietética. Seus efeitos fisiológicos estão intimamente relacionados com suas propriedades físico-químicas, tais como solubilidade, viscosidade, hidratação e capacidade de troca iônica no aparelho digestivo.

As algas são fonte de fitoquímicos biologicamente ativos, que incluem carotenoides, ficobilinas, ácidos graxos, polissacarídeos, vitaminas, esterois de tocoferol e ficocianinas, entre outros. Muitos desses compostos foram reconhecidos pela atividade biológica benéfica para a saúde humana e animal. Alguns dos potenciais benefícios incluem o controle de hiperlipidemia, trombose, tumores e obesidade (PLAZA, CIFUENTES e IBANEZ, 2008).

As algas podem estar associadas ao estágio evolutivo superior, levando à produção de metabólitos secundários diversificados e consequentemente à expressão de inúmeras atividades biológicas. São capazes de sintetizar metabólitos halogenados que podem pertencer à praticamente todas as classes químicas, desde hidrocarbonetos de cadeia curta, cetonas simples, fenois e acetogeninas até sofisticados terpenos (CARVALHO e ROQUE, 2000).

As algas marinhas pardas e verdes são menos eficientes na produção de substâncias halogenadas, sendo que ambas e, particularmente as pardas, apresentam polissacarídeos sulfatados (VAN DEN HOEK, MANN e JAHNS, 1997).

Como defesas químicas, as algas produzem acetogeninas, terpenos, derivados de aminoácidos, fenois simples e polifenois, substâncias que diferem dos produtos de plantas por serem frequentemente halogenados (CARVALHO e ROQUE, 2000).

Dentre a classe dos fenois, os bromados são substâncias muito estudadas em algas marinhas. O lanosol (éter metílico do álcool 2,3-dibromo-4,5-diidroxibenzílico) está entre os bromofenois mais amplamente distribuídos, sendo encontrado tanto em micro quanto em macroalgas. Esse composto, de acordo com a literatura, apresenta efeito algicida, antiinflamatório e antibiótico (CARVALHO e ROQUE, 2000). Derivados halogenados do ácido hidroxibenzoico e ésteres do ácido cinâmico também foram citados em algas (ONOFREJOVÁ et al., 2010). Uma série de compostos fenólicos, tais como catequinas, flavonois e flavonois glicosilados têm sido identificados em extratos metanólicos de algas vermelhas e pardas (SANTOSO, YOSHIE e SUZUKI, 2002; YOSHIE-STARK, HSIEH e SUZUKI, 2003).

Os florotaninos, grupo de compostos fenólicos restritos a polímeros do floroglucinol, têm sido identificados em muitas famílias de algas pardas, tais como Alariaceae, Fucaceae e Sargassaceae. Vários estudos têm mostrado que os florotaninos são o único grupo fenólico detectado em algas pardas (KOIVIKKO et al., 2007).

No Brasil, as pesquisas com produtos naturais de origem marinha, particularmente as algas, tiveram início na década de 60 . Naquela época, houve grande investimento por parte das indústrias farmacêuticas na busca de substâncias bioativas a partir dos organismos que vivem nos oceanos. Pode-se dizer que a química de produtos naturais marinhos, incipiente na década de 1970, desenvolveu-se rapidamente nos anos 80 e amadureceu na década de 90 (FAULKNER, 2000). No entanto, a maioria das informações científicas refere-se à composição química e à aplicabilidade 
desses organismos, muitos dos quais são espécies endêmicas. Devido à diversidade de espécies, há grande potencial de pesquisa para a área, principalmente com relação à atividade biológica apresentada pelas algas (PINTO et al., 2002).

Esta revisão de literatura teve como objetivo apresentar os produtos de algas marinhas disponíveis, as atividades antioxidante e antimicrobiana por elas apresentadas, os principais compostos envolvidos nessas bioatividades, além de aspectos fundamentais sobre a exploração e comercialização desses produtos naturais.

\section{PRODUTOS DE ALGAS MARINHAS}

O consumo de algas está sujeito à regulamentação específica e os detalhes de sua composição química e as variações entre as espécies são necessárias para obtenção de autorização para seu uso na alimentação humana. A França foi o primeiro país europeu a estabelecer regulamentação específica sobre o uso de algas marinhas para consumo humano. As algas na Espanha são consideradas como novos alimentos e para efeito de controlar o limite máximo de contaminantes que apresentam foram incluídas no grupo de vegetais enlatados (RD, 2420/78), mas não há regulamentação específica para os produtos derivados de algas e seu consumo é limitado (ESPANHA, 1978).

As algas vermelhas são eficientes na produção de polissacarídeos sulfatados, como as carragenas e o ágar que chegam a representar mais de $70 \%$ do seu peso e têm razoável valor comercial (VAN DEN HOEK, MANN e JAHNS, 1997).

O hidrocoloide carragena é usado na produção de alimentos, principalmente pelas indústrias de laticínios (iogurtes, flans, sorvetes, achocolatados) e embutidos (salsichas, presuntos), para a fabricação de gelatinas e geleias, e como espessante em molhos e sopas (VIDOTTI e ROLLEMBERG, 2004). Também apresentam diversas aplicações em indústrias não alimentícias (tintas, têxteis e perfumes) e farmacêuticas (produtos anticoagulantes e antiinflamatórios) (ARMISEN, 1995). A macroalga Kappaphycus alvarezii tem sido cultivada em larga escala para suprir as indústrias alimentícias de carragena. Várias atividades biológicas têm sido descritas para a carragena, tais como antitumoral, antiviral, anticoagulante e imunomodulatória (ZHOU et al., 2004; ZHOU et al., 2005).

Carragenas são polissacarídeos sulfatados lineares de D-galactose e 3,6-anidro-Dgalactose extraídos de certas algas vermelhas da classe Rhodophyceae. Têm sido amplamente utilizados na indústria alimentícia, como espessante, geleificante e proteína-agente de suspensão, e pela indústria farmacêutica como excipiente em comprimidos. Além das atividades biológicas conhecidas relacionadas com inflamação e respostas imunes, carragenas são potentes inibidores dos vírus da herpes e do papiloma humano (HPV) e há indícios de que possam oferecer alguma proteção contra a infecção pelo vírus da imunodeficiência humana (HIV). Segundo alguns autores, a carragena é ativa contra o HIV somente em concentrações cerca de 100 vezes maiores que as necessárias para inibir o papilomavírus (BUCK et al., 2006). No entanto, carragenas podem servir como modelos para projetar novos agentes anti-HIV, melhorando as suas propriedades terapêuticas por meio de modificações químicas (CAMPO et al., 2009).

$\mathrm{Na}$ indústria alimentícia, as carragenas são largamente utilizadas devido à suas excelentes propriedades físico-funcionais (espessante, gelificante e estabilizante). Melhoram a textura do queijo cottage, controlam a viscosidade e a textura de doces e sobremesas, além de atuarem como aglutinantes e estabilizadores na indústria de processamento de carne para a fabricação de salsichas e hambúrgueres com baixo teor de gordura.

Os alimentos respondem por $70-80 \%$ da produção mundial de carragena, estimada em cerca de 45.000 toneladas métricas por ano, sendo destinado $45 \%$ para os produtos lácteos e $30 \%$ para a carne e seus derivados. O mercado total de carragenas foi estimado em 300 milhões de dólares/ano (MCHUGH, 2003). 
A qualidade do ágar depende de suas características físico-químicas e também de parâmetros ambientais (DAUGHERTY e BIRD, 1988). O ágar de baixa qualidade é usado em produtos alimentícios (congelados, sucos de frutas e sobremesas). Outras aplicações industriais incluem adesivos e tintas. $O$ ágar de média qualidade é empregado como substrato em meios de cultura bacteriológicos. Também são importantes na indústria médica e farmacêutica para a fabricação de supositórios, cápsulas e anticoagulantes. Os tipos mais purificados, ou seja, as frações neutras chamadas de agarose são usadas para separação em técnicas de biologia molecular (eletroforese, imunodifusão e cromatografia em gel) (CARDOZO et al., 2007).

As algas pardas são utilizadas na alimentação humana e também como fertilizantes, constituindo importante fonte de ácidos algínicos ou alginatos, cujas propriedades coloidais são aproveitadas na farmacologia (por exemplo, em pomadas e suspensões). Os alginatos também são utilizados na indústria alimentícia e farmacêutica devido à sua habilidade de sequestrar íons metálicos e formar solução altamente viscosa (YAMASAKI et al., 2005).

As algas constituem importante fonte de compostos nutricionais, que estão descritos na Tabela 1.

TABELA 1 - PRINCIPAIS COMPOSTOS ENCONTRADOS EM ALGAS MARINHAS

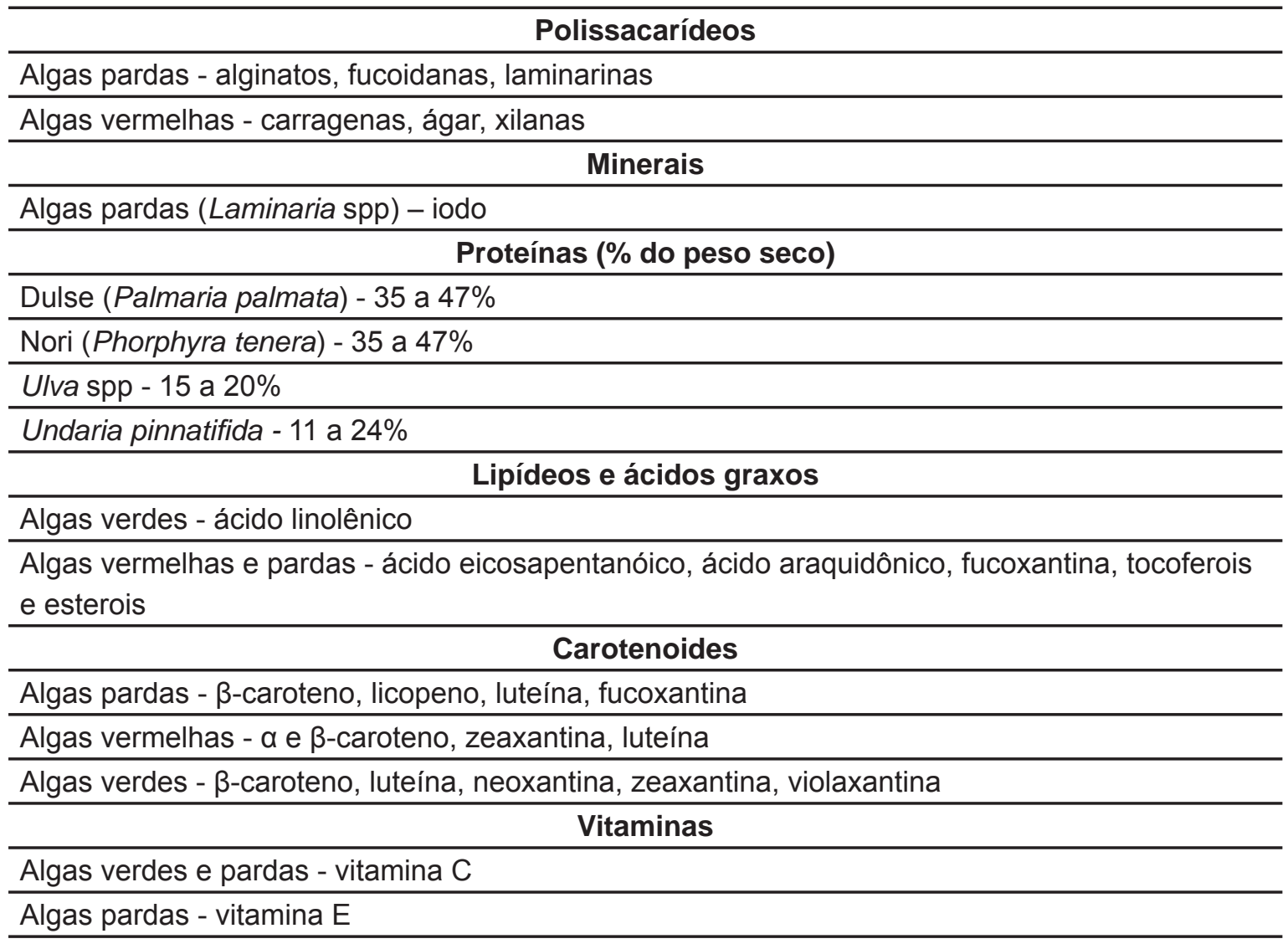

Fonte: BURTIN, 2003

\section{ATIVIDADE ANTIOXIDANTE DAS ALGAS MARINHAS}

Embora as plantas que realizam fotossíntese estejam, em sua maioria, expostas à combinação de fatores (como altas concentrações de oxigênio e luz) que levam à formação de radicais livres e outros agentes oxidantes fortes, as algas raramente sofrem algum dano oxidativo grave in vivo (AHN et al., 2004). 
Segundo Raimundo, Horta e Fett (2004), apesar do seu alto conteúdo de ácidos graxos poliinsaturados, as algas demonstram estabilidade frente à oxidação durante seu armazenamento. As algas também são sempre submetidas a rápidas variações de intensidade de luz e concentrações de $\mathrm{O}_{2}$ e $\mathrm{CO}_{2}$ ao longo da coluna de água, combinação que origina radicais livres, bem como outros potentes oxidantes. Assim, a ausência de danos oxidativos e sua sobrevivência dependem da resposta eficiente ao estresse oxidativo. Por essa razão, tais organismos podem representar importante fonte de substâncias antioxidantes naturais tanto para as indústrias alimentícias como para as farmacêuticas (MATSUKAWA et al., 2007).

A definição mais aceita para antioxidantes abrange as substâncias que mesmo presentes em baixas concentrações em relação ao substrato oxidante podem atrasar ou inibir as taxas de oxidação (SIES, 1993). Vários componentes fisiológicos são conhecidos pela capacidade de inativar ou neutralizar radicais livres, dentre os quais diversos metabólitos secundários provenientes de produtos naturais (PIETTA, 2000; NORDBERG e ARNÉR, 2001).

O interesse pelo estudo de substâncias com atividade antioxidante em algas surgiu no Japão, durante a busca de novos aditivos para alimentos em substituição aos antioxidantes sintéticos hidroxianisol butilado (BHA) e hidroxitolueno butilado (BHT). Esses compostos têm demonstrado efeitos carcinogênicos, alterações enzimáticas e alterações lipídicas em animais. Entretanto, há algumas desvantagens no uso de produtos naturais como, carotenoides, compostos fenólicos e vitamina $\mathrm{E}$. $\mathrm{O}$ fato desses compostos serem insolúveis em água dificulta sua aplicação pela indústria. Alguns compostos naturais solúveis em água também apresentam algumas limitações, como a vitamina $\mathrm{C}$, que é extremamente sensível ao aquecimento e se desnatura facilmente. Nesse sentido, as algas marinhas vêm sendo estudadas há décadas como alternativa para essas dificuldades tecnológicas (RUPEREZ, AHRAZEM e LEAL, 2002). O fato de algumas algas desidratadas poderem ser armazenadas por longos períodos sem o perigo de deterioração oxidativa, mesmo apresentando mais de $30 \%$ do total de seus ácidos graxos na forma de cadeias poliinsaturadas, despertou o interesse dos pesquisadores em relação ao seu mecanismo antioxidante (ROCHA et al., 2007).

AHN et al. (2004) investigaram a atividade de sequestro de radical livre pelo método do DPPH em extratos solúveis em água, obtidos pela hidrólise enzimática com proteases e carboidrases de algas pardas da espécie Scytosiphon lomentaria. Não encontraram atividade antioxidante satisfatória nos extratos hidrolisados de algas marinhas e salientaram que apesar da vantagem da solubilidade em água, há a necessidade de maiores estudos para viabilizar o uso desses tipos de extratos como antioxidantes naturais.

As macroalgas são similares às plantas terrestres no que concerne à produção de substâncias genericamente denominadas de metabólitos secundários, tais como terpenos, compostos aromáticos, acetogeninas, derivados de aminoácidos e principalmente os polifenois (halogenados e sulfatados). Esses compostos conferem às algas expressiva atividade antioxidante, descrita em vários trabalhos na literatura. Nagai e Yukimoto (2003) avaliaram a atividade antioxidante de bebidas preparadas com quatro espécies de algas, comuns na culinária japonesa: Ecklonia cava (trombetado-mar), Undaria pinnatifida (wakame), Hizikia fusiforme ("hizikia") e Ulva pertusa (alface-do-mar). Tais autores descreveram que as algas apresentam bom potencial antioxidante, sendo a trombetado-mar a mais eficiente. Além disso, encontraram correlação positiva entre o teor de polifenois e a atividade antioxidante expressa pelas algas.

A avaliação in vivo de galactana sulfatada, proveniente de fração da alga vermelha Porphyra haitanensis, demonstrou expressiva atividade antioxidante em ratos. A administração intraperitoneal da fração contendo o composto diminuiu significativamente a peroxidação lipídica em ratos, além de aumentar a capacidade antioxidante e a atividade da superóxido dismutase e glutationa peroxidase (ZHANG et al., 2004).

O efeito antioxidante de quatro espécies de algas do filo Chlorophyta foi avaliado por meio da inibição da peroxidação do ácido linoleico em emulsão. As espécies mais efetivas foram Enteromorpha intestinalis e Chaetomorpha antenina, com porcentagens de inibição acima de $70 \%$. 
Além disso, o teor de compostos fenólicos foi medido, sendo obtidos valores de $610,31 \mathrm{mg} / 100 \mathrm{~g}$ e 635,53 mg/100 g para as algas mais bioativas, respectivamente (RAYMUNDO, HORTA e FETT, 2004).

Palmaria palmata (dulse) teve seu teor de compostos fenólicos e sua atividade antioxidante avaliada por Yuan, Bone e Carrington (2005). Foi encontrado teor de 10,3 $\mu \mathrm{g}$ de compostos fenólicos/ $\mathrm{mg}$ de extrato da alga e alta atividade antioxidante pelos métodos de sequestro de radical DPPH e $\mathrm{ABTS}^{+}$e inibição das substâncias reativas ao ácido tiobarbitúrico (TBARS). Esses autores associaram a atividade antioxidante aos compostos solúveis em soluções de álcool/água, caracterizadas por grupamentos funcionais fenólicos.

Duan et al. (2006) determinaram a atividade antioxidante de extratos brutos de Polysiphonia urceolata pelos métodos de sequestro de radical livre DPPH e sistema $\beta$-caroteno/ácido linoleico. Os resultados demonstraram alta atividade antioxidante dessa alga vermelha quando comparada aos padrões BHT, ácido gálico e ácido ascórbico.

Ao avaliarem o teor de fenólicos e o poder redutor de Palmaria palmata, Laminaria setchellii, Macrocystis integrifolia e Nereocystis leutkeana, Yuan e Walsh (2006) relataram que essas espécies apresentam alto poder redutor e teor de fenólicos que variaram de 1,84 a $12,8 \mu \mathrm{g} / \mathrm{mg}$ de extrato. Além disso, verificaram correlação positiva entre a atividade e o teor de fenólicos, sugerindo que os florotaninos e polifenois (dentre os quais os ácidos fenólicos) são responsáveis pela bioatividade dessas algas.

Nahas et al. (2007), avaliando a capacidade de sequestro de radicais livres de treze espécies de algas pelos métodos do DPPH e quimioluminescência, verificam que os extratos da alga parda Taonia atomaria exibiram a maior atividade. Usando a separação cromatográfica, seguida por Cromatografia a Líquido de Alta Eficiência em modo preparativo, tais autores isolaram seis metabólitos bioativos (taondiol, isoepitaondiol, estipodiol, estipoldiona, sargaquinona e sargaol).

A alga parda Ecklonia cava teve sua atividade antioxidante avaliada por Li et al. (2009) mediante fracionamento e purificação bioguiados. Encontraram sete florotaninos com expressiva atividade que podem ser utilizados como antioxidantes naturais nas indústrias farmacêuticas e cosméticas, bem como usados como alimentos funcionais (LI et al., 2009).

\section{ATIVIDADE ANTIMICROBIANA DAS ALGAS MARINHAS}

Em comparação aos inúmeros trabalhos sobre a atividade antioxidante das algas marinhas, a atividade antimicrobiana dos extratos obtidos desses organismos é pouco relatada na literatura. De acordo com $\mathrm{OH}$ et al.(2008), os polifenois halogenados presentes nas algas, dentre os quais os bromofenois, são os compostos majoritariamente responsáveis pela expressiva atividade antimicrobiana que as algas tem demonstrado. Além dos metabólitos secundários, as algas também apresentam em sua composição química, ácidos, alcaloides e aminas, substâncias que thes conferem forte atividade antimicrobiana (HELLIO et al., 2000; LAM e HARDER, 2007).

A atividade antimicrobiana de extratos obtidos de Bifurcaria bifurcata foi avaliada de acordo com a variação sazonal em Cobetia marina e Pseudoalteromonas haloplanktis. Foi verificado que a máxima atividade antimicrobiana pode ser obtida em algas coletadas entre abril e julho, quando a temperatura da água e a luminosidade apresentam-se mais altas na França (MARÉCHAL et al., 2004).

A atividade antimicrobiana de extratos da alga Cystoseira barbata foi investigada em bactérias Gram-positivas, Gram-negativas e Candida albicans. O extrato hexânico demonstrou maior atividade que os extratos metanólico, diclorometânico e clorofórmico. Além disso, foi constatado que os óleos voláteis dessa alga não apresentaram atividade antimicrobiana (OZDEMIR et al., 2006).

Kuda et al. (2007) avaliaram a atividade antibacteriana de duas espécies do gênero Ecklonia (E. stolonifera e E. kurome) em cepas de E. coli, P. aeruginosa, S. aureus e B. cereus. 
Observaram que as algas apresentaram atividade contra todas as bactérias, com exceção de E. coli. Nagayama et al. (2002) descreveram que os florotaninos de E. kurome apresentam forte atividade bactericida.

Uma série de bromofenois foi isolada da alga vermelha Odonthalia corymbifera e sua atividade antimicrobiana avaliada em bactérias Gram-negativas, Gram-positivas e fungos. Entre os isolados, o 2,2,3,3-tetrabromo-6,6-diidroxidifenilmetano monstrou-se mais ativo contra Candida albicans, Aspergillus fumigatus, Trichophyton rubrum e Trichophyton mentagrophytes. O bromofenol sintético 3,3-dibromo-6,6-diidroxidifenilmetano e 3,3,5,5-tetrabromo-6,6-diidroxidifenilmetano apresentaram potente efeito antimicrobiano para Staphylococcus aureus, Bacillus subtilis, Micrococcus luteus, Proteus vulgaris, e Salmonella typhimurium (OH et al., 2008).

DUBBER e HARDER (2008) investigaram os efeitos antimicrobianos dos extratos hexânico e metanólico das algas Mastocarpus stellatus, Laminaria digitata e Ceramium rubrum em 19 bactérias patogênicas de peixes. $O$ extrato metanólico de $C$. rubrum a $10 \mathrm{mg} / \mathrm{mL}$ e o extrato hexânico de L. digitata a $31 \mathrm{mg} / \mathrm{mL}$ demonstraram forte atividade antimicrobiana e inibiram todas as bactérias testadas. A alta susceptibilidade dessas bactérias corroboram os resultados de estudo prévio no qual 26 espécies de algas cultivadas tiveram sua atividade antimicrobiana testada em 5 bactérias patogênicas de peixes (BANSEMIR et al., 2006).

\section{EXPLORAÇÃO E COMERCIALIZAÇÃO DE ALGAS MARINHAS}

Anualmente são colhidas cerca de 4 milhões de toneladas de algas em todo o mundo, sendo os principais produtores os chineses e os japoneses. As algas permitem a obtenção de produtos de baixo custo e importantes para a vida do homem moderno, com valores que ultrapassam alguns bilhões de dólares por ano (VIDOTTI e ROLLEMBERG, 2004).

A importância das algas marinhas na América Latina, como recurso renovável, vem crescendo continuamente porque seus volumes cada vez maiores de extração geram importantes divisas econômicas para o país produtor (OLIVEIRA, 1997).

A demanda da indústria brasileira por algas e seus derivados está crescendo consideravelmente, mas sua exploração e a produção de ficocoloides no Brasil é relativamente recente e ainda bastante baixa. Entre os anos de 1990 e 1995, o consumo brasileiro de algas e derivados dobrou, entretanto a demanda interna é suprida principalmente por importações. A importação de ágar aumentou em $400 \%$ e a de alginatos, medicamentos e produtos alimentares derivados de algas em $200 \%$ em duas décadas (CUNHA et al., 1999).

Outros países da América do Sul estão muito mais adiantados que o Brasil na produção e extração de algas, embora o país seja reconhecido como avançado em nível acadêmico (SANTOS e GOMES, 2006).

Entre as algas comestíveis "in natura" existentes em águas brasileiras destacam-se as do gênero Porphyra, o mesmo da Nori japonesa. Porém, a Porphyra brasileira ainda não tem mercado de consumo interno e a competição com os japoneses e chineses não compensa. Tais povos estão escolhendo as melhores linhagens para cultivo há séculos e garantindo melhor qualidade, além da quantidade produzida (SANTOS e GOMES, 2006).

\section{CONCLUSÃO}

Os dados descritos na literatura evidenciam o grande potencial das algas marinhas como fontes naturais de ingredientes funcionais. Os compostos biologicamente ativos podem ser largamente utilizados nas indústrias de alimentos, cosmética e farmacêutica. Porém, é interessante ressaltar que uma vez demonstrada sua conveniência, outros aspectos devem ser avaliados, tais como: a produção de ingredientes em escala industrial, a extração e purificação dos compostos bioativos e a relação custo-benefício da produção e aplicação desses compostos. 


\section{ABSTRACT \\ NATURAL PRODUCTS OF SEAWEEDS AND THEIR ANTIOXIDANT AND ANTIMICROBIAL POTENTIAL}

This literature review aimed to present the available seaweeds products, its antioxidants and antimicrobial activities, the main compounds involved in these bioactivities, as well as fundamental aspects regarding these natural products utilization and marketing. Reported data indicate great potential of seaweeds as natural sources of functional ingredients. The study of chemical composition, in addition to the discovery of action mechanisms that involve biological activities of various seaweeds species, will be an interesting source of data, to the explanation of new drugs of interest to the pharmaceutical and cosmetic industry, and also of new functional ingredients to the food industry.

KEY-WORDS: SEAWEEDS; ANTIOXIDANT ACTIVITY; ANTIMICROBIAL ACTIVITY.

\section{REFERÊNCIAS}

1 AHN, C.B.; JEON, Y.J.; KANG, D.S.; SHIN, T.S.; JUNG, B.M. Free radical scavenging activity of enzymatic extracts from a brown seaweed Scytosiphon lomentaria by electron spin resonance spectrometry. Food Research International, v. 37, p. 253-258, 2004.

2 ARMISEN R. World-wide use and importance of Gracilaria. Journal of Applied Phycology, v. 7, n. 1, p. 231-243, 1995.

3 BANSEMIR, A.; BLUME, M.; SCHRODER, S.; LINDEQUIST, U. Screening of cultivated seaweeds for antibacterial activity against fish pathogenic bacteria. Aquaculture,v. 252, n. 1, p. 79-84, 2006.

4 BUCK, C. B.; THOMPSON, C. D.; ROBERTS, J. N.; MULLER, M.; LOWY, D. R.; SCHILLER, J. T. Carrageenan is a potent inhibitor of papillomavirus infection. PLoS Pathogens, v.2, p. 671-680, 2006.

5 BURTIN, P. Nutritional value of seaweeds. Electronic Journal of Environmental, Agriculture and Food Chemistry, v.2, n.4, p. 498-503, 2003.

6 CAMPO, V.L.; KAWANO, D.F.; DA SILVA, J.R.; CARVALHO, I. Carrageenans: biological properties, chemical modifications and structural analysis - a review. Carbohydrate Polymers, v. 77, p. 167-180, 2009.

7 CAMPOS, V.B.; BARBARINO, E; LOURENÇO, S.O. Crescimento e composicão química de dez espécies de microalgas marinhas em cultivos estanques. Ciência Rural, v. 40, n. 2, p. 339-47, 2010.

8 CARDOZO, K.H.M.; GUARATINI, T.; BARROS, M.P.; FALCÃO, V.R.; TONON, A.P.; LOPES, N.P. Metabolites from algae with economical impact. Comparative Biochemistry and Physiology, v. 146, p. 60-78, 2007.

9 CARVALHO, L.R.; ROQUE, N.F. Fenóis halogenados e/ou sulfatados de macroalgas marinhas. Química Nova, v. 23, n. 6, p. 757-764, 2000.

10 CUNHA, S.R.; PAZETO, F.D.; CRESTANI, D.E.V.; LIMA, G.B.; NASCIMENTO, J.; SANT'ANNA, F.; MANZONI, G.C.; MARENZI, A.W.C.; MAFRA, J.R. Potencial de crescimento de macroalgas cultiváveis presentes na enseada de armação do Itapocory (Penha, SC): avaliação preliminar. Notas Tec. Facimar, v.3, p.17-25, 1999.

11 DAUGHERTY, K.B.; BIRD, T.K. Salinity and temperature effects on agar production from Gracilaria verrucosa strain G-16. Aquaculture, v. 75, p. 105 -113, 1988.

12 DHARGALKAR, V.K.; VERLECAR, X.C. Southern Ocean seaweeds: a resource for exploration in food and drugs. Aquaculture, v. 287, n.1, p. 229 - 242, 2009.

13 DUAN, X.J.; ZHANG, W.W.; LI, X.L.; WANG, B.G. Evaluation of antioxidant property of extract and fractions obtained from a red alga, Polysiphonia urceolata. Food Chemistry, v. 95, p. 37-43, 2006. 
14 DUBBER, D.; HARDER, T. Extracts of Ceramium rubrum, Mastocarpus stellatus and Laminaria digitata inhibit growth of marine and fish pathogenic bacteria at ecologically realistic concentrations. Aquaculture, v. 274 , n. 1 , p. $196-200,2008$.

15 ESPANHA. Real Decreto 2420/78, de 2 de junho de 1978. Se aprueba la Reglamentación técnico sanitaria para la elaboración y venta de conservas y semiconservas vegetales. Boletin Oficial Del Estado, Madri, v.1, n. 244, p. 23702, 12 dez.1978.

16 FAULKNER, D.J. Marine natural products. Natural Products Reports, v. 17, p. 7-55, 2000.

17 GÓMEZ-ORDÓÑEZ, E.; JIMÉNEZ-ESCRIG, A.; RUPÉREZ, P. Dietary fibre and physicochemical properties of several edible seaweeds from the northwestern Spanish coast. Food Research International, v. 43, p. 2289-2294, 2010.

18 HELLIO, C.; BREMER, G.; PONS, A.M.; LE GAL, Y.; BOURGOUGNON. N. Inhibition of the development of microorganisms (bacteria and fungi) by extracts of marine algae from Brittany, France. Applied Microbiology and Biotechnology, v. 54, n. 4, p. 543-549, 2000.

19 HORTA, P.A. Macroalgas do infralitoral do sul e sudeste do Brasil: taxonomia e biogeografia. 2000. 301 p. Tese (Doutorado em Ciências), Universidade de São Paulo, São Paulo, 2000.

20 KADAM, S.U.; PRABHASANKAR, P. Marine foods as functional ingredients in bakery and pasta products. Food Research International, v. 43, p.1975-1980, 2010.

21 KOIVIKKO, R,; LOPONEN, J,; PIHLAJA, K.; JORMALAINEN, V. High-performance liquid chromatographic analysis of phlorotannins from the brown alga Fucus vesiculosus. Phytochemistry Analysis, v. 18, n. 4, p. 326-332, 2008.

22 KUDA, T.; GOTO, T.K.H.; SUZIKI, T.; YANO, T. Varieties of antioxidant and antibacterial properties of Ecklonia stolonifera and Ecklonia kurome products harvested and processed in the Noto peninsula, Japan. Food Chemistry, v. 103, n. 1, p. 900-905, 2007.

23 LAM, C.; HARDER, T. Marine macroalgae affect abundance and community richness of bacterioplankton in close proximity. Journal of Phycology, v. 43, n. 1, p. 874-881, 2007.

24 LI, Y.; QIAN, Z.J.; RYU, B.; LEE, S.H.; KIM, M.M.; KIM, S.K. Chemical components and its antioxidant properties "in vitro": an edible marine brown alga, Ecklonia cava. Bioorganic \& Medicinal Chemistry, v. 17, n. 5, p. 1963-1973, 2009.

25 MARÉCHAL, J.P.; CULIOLIB, G.; HELLIOAB, C.; THOMAS-GUYONC, H; CALLOWD, M.E.; CLAREA, A.S. Seasonal variation in antifouling activity of crude extracts of the brown alga Bifurcaria bifurcata (Cystoseiraceae) against cyprids of Balanus amphitrite and the marine bacteria Cobetia marina and Pseudoalteromonas haloplanktis. Journal of Experimental Marine Biology and Ecology, v. 313, p. 4762, 2003.

26 MATSUKAWA, R.; DUBINSKY, Z.; KISHIMOTO, E.; MASAKI, K.; MASUDA, Y.; TAKEUCHI, T. A comparison of screening methods for antioxidant activity in seaweeds. Journal of Applied Phycology, v. 9, n. 1, p. 2935, 1997.

$27 \mathrm{McHUGH}$, D.J. A guide to the seaweed industry. Roma: FAO, 2003. p. 118. (FAO Fisheries Paper, 441).

28 NAGAI, T.; YUKIMOTO, T. Preparation and functional properties of beverages made from sea algae. Food Chemistry, v. 81, p. 327-332, 2003.

29 NAGAYAMA, K.; IWAMURA, Y.; SHIBATA, T.; HIRAYAMA, I.; NAKAMURA, T. Bactericidal activity phlorotanins from the brown alga Ecklonia kurome. Journal of Antimicrobial Chemotheraphy, v. 50, p. 889-893, 2002.

30 NAHAS, R.; ABATIS, D.; ANAGNOSTOPOULOU, M.A.; KEFALAS, P.; VAGIAS, C.; ROUSSIS, V. Radicalscavenging activity of Aegean Sea marine algae. Food Chemistry, v. 102, n. 1, p. 577-581, 2007.

31 NORDBERG, J.; ARNÉR, S.J. Reactive oxygen species, antioxidants, and the mammalian thioredoxin system. Free Radical Biology \& Medicine, v. 31, p. 1287-1312, 2001. 
$32 \mathrm{OH}$, K.B.; LEE, J.H.; CHUNG, S.C.; SHIN, J.; SHIN, H.J.; KIM, H.K. Antimicrobial activities of the bromophenols from the red alga Odonthalia corymbifera and some synthetic derivatives. Bioorganic and Medicinal Chemistry Letters, v. 8, n. 1, p. 104-108, 2008.

33 OLIVEIRA, E.C. Algas marinhas: um recurso ainda pouco explorado pelo Brasil. Panorama da Aquicultura, v. 6, n. 7, p. 24-26, 1997.

34 ONOFREJOVÁ, L.; VASICKOVÁ, J.; KLEJDUS, B.; STRATIL, P.; MISURCOVÁ, L.; KRÁCMAR, S.; KOPECKY, J.; VACEK, J. Bioactive phenols in algae: the application of pressurized-liquid and solid-phase extraction techniques. Journal of Pharmaceutical and Biomedical Analysis, v. 51, n. 2, p. 464-470, 2010.

35 OZDEMIR, G.; HORZUM, Z.; SUKATAR, A.; KARABAY-YAVASOGLU, N.U. Antimicrobial activities of volatile components and various extracts of Cystoceira barbata from the Coast of Izmir, Turkey. PharmacologyBiology, v. 44, n. 3, p.183-188, 2006.

36 PINTO, A.C.; SILVA, D.H.S.; BOLZANI, V.S.; LOPES, N.P.; EPIFANIO, R.A. Produtos naturais: atualidade, desafios e perspectivas. Química Nova, v. 25, n. 1, p. 45-61, 2002.

37 PIETTA, P.G. Flavonoids as antioxidants. Journal of Natural Products, v. 63, p. 1035-1042, 2000.

38 PLAZA, M.; CIFUENTES, A.; IBÁÑEZ E. In the search of new functional food ingredients from algae. Trends in Food Science \& Technology, v. 19, n. 1, p. 31-39, 2008.

39 RAYMUNDO, M.S.; HORTA, P.; FETT, R. Atividade antioxidante in vitro de extratos de algumas algas verdes (Chlorophyta) do litoral catarinense (Brasil). Revista Brasileira de Ciências Farmacêuticas, v. 40, n. 4, p. 495-503, 2004.

40 ROCHA, I.P. Aqüicultura: um excelente negócio. Revista Brasileira de Agropecuária, v.11, p. 6-12, 2001.

41 ROCHA, F.D.; PEREIRA, R.C.; KAPLAN, M.A.C.; TEIXEIRA, V.L. Produtos naturais de algas marinhas e seu potencial antioxidante. Revista Brasileira de Farmacognosia, v. 17, n. 4, p. 631-639, 2007.

42 RUPEREZ, P.; AHRAZEM, O.; LEAL, J. A. Potential antioxidant capacity of sulfated polysaccharides from the edible marine brown seaweed Fucus vesiculosus. Journal of Agricultural and Food Chemistry, v. 50, p. 840-845, 2002.

43 SANTOS, W.A.; GOMES, E.A. Importância econômica dos costões rochosos. Saúde \& Ambiente em Revista, v. 1, n. 2, p. 51-59, 2006.

44 SANTOSO, J.; YOSHIE, Y.; SUZUKI, T. The distribution and profile of nutrients and catechins of some Indonesian seaweeds. Fisheries Science, v. 68, (supplement), p. 1647-1648, 2002.

45 SOUSA, M. B.; PIRES, K. M. S.; ALENCAR, D. B.; SAMPAIO, A. H.; SAKER-SAMPAIO, S. $\alpha$, $\beta$-caroteno e a-tocoferol em algas marinhas "in natura". Ciência e Tecnologia de Alimentos, v. 28, n. 4, p.953-958, 2008.

46 VAN DEN HOEK, C.; MANN, D.G.; JAHNS, H.M. Algae: an introduction to physiology. Cambridge: Academic Press, 1997.

47 VIDOTTI, E.C.; ROLLEMBERG, M.C.E. Algas: da economia nos ambientes aquáticos à biorremediação e à química analítica. Química Nova, v. 27, n. 1, p.139-145, 2004.

48 YAMASAKI, M.; OGURA, K.; HASHIMOTO, W.; MIKAMI, B.; MURATA, K. A structural basis for depolymerization of alginate by polysaccharide lyase family-7. Journal of Molecular Biology, v. 352, p. 11-21, 2005.

49 YOSHIE-STARK, Y.; HSIEH, Y.P.; SUZUKI, T. Distribution of flavonoids and related compounds from seaweeds in Japan. Journal of Tokyo University of Fisheries, v. 89, n. 1, p. 1-6, 2003.

50 YUAN, Y.V.; BONE, D.E.; CARRINGTON, A. Antioxidant activity of dulse (Palmaria palmate) extract evaluated "in vitro". Food Chemistry, v. 91, p. 485-494, 2005.

51 YUAN, Y.V.; WALSH, N.A. Antioxidant and antiproliferative activities of extracts from a variety of edible seaweeds. Food and Chemistry Toxicology, v. 44, n. 1, p. 1144-1150, 2006. 
52 ZHANG, Q.; LI, N.; LIU, X.; ZHAO, Z.; LI, Z.; XU, Z. The structure of a sulfated galactan from Porphyra haitanensis and its "in vivo" antioxidant activity. Carbohydrate Research, v. 339, p. 105-111, 2004.

53 ZHOU, G.F.; SUN, Y.; XIN, H.; ZHANG, Y.; LI, Z.; XU, Z. "In vivo" antitumor and immunomodulation activities of different molecular weight lambda-carrageenans from Chrondus Ocellatus. Pharmacology Research, v. 50 , p. 47-53, 2004

54 ZHOU, G.F.; XIN, H.; SHENG, W.; SUN, Y.; LI, Z.; XU, Z. "In vivo" growth-inhibition of S180 tumor by mixture of \%-Fu and low molecular lambda-carrageenan from Chrondus Ocellatus. Pharmacology Research, v. 51, p. 153-157, 2005. 